\title{
Freckle Formation and Thermodynamic Assessment for Nb-bearing Superalloys
}

\author{
Zhengdong Long, Wanhong Yang, Keh-Minn Chang \\ Dept. of Mechanical and Aerospace Engineering, West Virginia University \\ PO Box 6106, Morgantown, WV 26505
}

\begin{abstract}
IN718, IN625 and IN706 are wildly used Nb-bearing cast-wrought superalloys. With the ever increasing demand for large ingot size to meet new design for aggressive jet engine and industrial land base engine, the solidification macrosegregation, i.e. freckle, becomes more and more concerned in recent years. The freckle is believed to be caused by instable convective flow in the mush zone, and the well-adopted approach to evaluate freckle formation tendency is through the calculation of Rayleigh Number $(\mathrm{Ra})$. However, it is difficult to calculate Ra due to complex solidification behaviors of multi-components superalloys.

In this paper, the freckles formed in $\mathrm{Nb}$-bearing superalloy were examined first. The thermodynamic calculation approach was then used to assess liquid composition as a function of temperature during the solidification under Scheil solidification condition. The relative $\mathrm{Ra}$ numbers for these alloys were calculated based on the results of thermodynamic calculation. Finally, this thermodynamic approach was evaluated through comparison with the calculation from semi-experimental results. The Ra numbers obtained by thermodynamic approach are in good agreement with ingot size capability of industry melting shops, which is believed to be limited mainly by freckle defect.
\end{abstract}

Superalloys 718, 625, 706 and Various Derivatives

Edited by E.A. Loria

TMS (The Minerals, Metals \& Materials Society), 2001 


\section{Introduction}

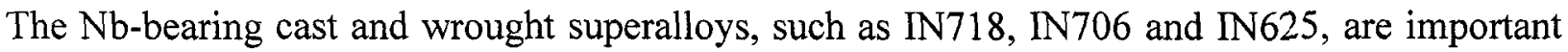
material used for key rotate components in aircraft and land based power engines. Table 1 gives the nominal chemical compositions of these Nb-bearing superalloys. Large jet engines and industrial gas turbine designs have increased the demand for large diameter superalloy ingots in recent years [1,2]. Obviously, the larger ingots are needed not only to achieve the final large component weight economically, but also to facilitate sufficient thermo-mechanical working to adequately breakdown the ingot structure and achieve all the final mechanical and structure requirements. However, the macrosegregation defect, especially the freckle, severely limits the increase of ingot size capability.

Many efforts [3-7] have been made concerning the mechanism and the criteria of freckle formation in large ingots. In order to simplify the analysis, the upward directional solidification was usually used to investigate the freckle problem [8,9]. The well-known theory is interdendritic fluid flow theory, in which the freckle is caused by the instable flow of soluteenriched interdendritic liquid in the mushy zone during the solidification. However, it is difficult to explain the freckle formation for remelting processes of large ingots, such as vacuum arc remelting (VAR) and electro-slag remelting (ESR). Based on VAR/ESR solidification conditions, the horizontal unidirectional solidification was used to simulate the freckle formation. In this paper, the macrostructure of test alloy, which has similar composition to IN718, was examined. The freckle in actual VAR solidification was also characterized.

In order to predict the macrosegregation freckle, it is important to build up a criterion to evaluate the freckle formation tendency. Several freckle criteria were proposed, and these criteria were evaluated by W. Yang recently [10]. The criterion given by Flemings and coworkers is found to predict the freckle formation satisfactorily. Rayleigh Number (Ra), as given in equation (1), was derived from this criterion. In this equation, the driven force to form freckle is liquid density difference, which is caused mainly by solute redistribution and liquid temperature during solidification. The resistance force is the permeability of interdendritic liquid flow, which is affected mainly by liquid faction and dendritic structure.

$$
R a=g \cdot \frac{\Delta \rho \Pi}{v f_{L}} \cdot \frac{1}{R}
$$

where, $\Delta \rho$ is liquid density difference, $g$ is gravity, $\Pi$ is permeability, $v$ is liquid viscosity, $f_{L}$ is liquid fraction, and $\mathrm{R}$ is crystal growth speed. In this paper, only the compositional effect on freckle formation is discussed. Therefore, the simplified equation (2) was used to calculate the relative $\mathrm{Ra}$.

$$
R a(\text { relative })=\frac{\Delta \rho \Pi}{f_{L}}
$$

The direct measurement of liquid density is difficult because of high melting temperature of alloys and complex interaction between alloying elements [11]. The molar fraction additive method is usually used to calculate the liquid density if the liquid molar fraction and temperature are known. The key factor to calculate $\mathrm{Ra}$ number is the relationship of liquid composition and temperature during solidification. In this paper, the thermodynamic simulation is used to assess the liquid composition and liquid temperature during the solidification. 
Table 1. The nominal composition of IN718, IN625 and IN706 alloys (wt\%)

\begin{tabular}{cccccccccc}
\hline Alloy & Ni & Fe & Cr & Al & Ti & Nb & Mo & C & B \\
\hline IN718 & Bal. & 18.5 & 19.0 & 0.5 & 0.9 & 5.1 & 3.0 & 0.04 & 0.002 \\
\hline IN625 & Bal. & 2.5 & 21.5 & 0.2 & 0.2 & 3.6 & 9.0 & 0.05 & -- \\
\hline IN706 & Bal. & 40.0 & 16.0 & 0.2 & 1.8 & 2.9 & -- & 0.03 & 0.002 \\
\hline
\end{tabular}

\section{Experimental and Analytical Procedures}

\section{Experimental Method}

The solidification of model alloy RN902 was carried out in a horizontal solidification furnace system. The ingot had a rectangular shape with a dimension of $220 \times 140 \times 20 \mathrm{~mm}$. The alloy was melted in an induction furnace and poured into the crucible. Unidirectional solidification was controlled by cooling from one side and heating from the other three sides. The chemical composition of the model alloy is Ni-20Cr- $18 \mathrm{Fe}-7 \mathrm{Nb}$, which is similar to commercial IN718 alloy. IN718 alloy was melted by VIM (vacuum induction melting) plus VAR (vacuum arc remelting) processing. The ingot diameter is $257 \mathrm{~mm}$, and freckle specimen was cut from around mid-radius. The optical and SEM (scanning electron microscope) were used to observe the macrostructure.

\section{Thermodynamic Approach}

Thermodynamics calculation through Gibbs energy is powerful to evaluate the stable state of existing phases. Based on the thermodynamics, the CALPHAD (CALculation of PHAse Diagrams) computational technique has been developed to calculate the phase equilibria and thermodynamic properties through Gibbs energy minimization approach [12]. Computational software to conduct the complicated calculation was developed. ThermoCalc ${ }^{\mathrm{TM}}$ (Version N) was used to conduct the solidification simulation. Although the ThermoCalc ${ }^{\mathrm{TM}}$ is only intended for equilibrium calculation, Scheil solidification simulation can be calculated by conforming to the local equilibrium assumption. The calculation starts with the nominal composition of the alloy and completely liquid phase in the system. By stepping with small decrement of temperature, we determine the new composition of the liquid. The solidification in the following step is calculated by resetting the new liquid composition as overall liquid composition. This method naturally treats the solidification with no solid diffusion and completely liquid diffusion. The outputs of Scheil module in ThermoCalc ${ }^{\mathrm{TM}}$ include liquid composition, temperature, and thermodynamic variables such as free energy, activity, entropy, enthalpy, and specific heats. Obviously, The accurate description of solidification of an alloy relies on a reliable database that includes the contributions of individual element and interactions between multiple elements. The updated $\mathrm{NiFe}$ and $\mathrm{Ni}$ database have been used, which is proven to be adequate for most superalloys [13].

\section{$\underline{\text { Semi-Experimental Approach }}$}

The Ra calculation procedure is basically same for this approach as the one mentioned above, except the method to obtain the relationship of liquid composition and temperature. For the semi-experimental approach, the compositions in segregated sample were measured at a large number of different points. The solutes profiles were obtained by systematic point count techniques, and regression was performed to establish the relationship of liquid composition at different liquid fractions during the solidification. The liquid temperature was measured by DTA (differential thermal analysis) 


\section{Results and Discussion}

\section{Macrostructure of Freckle}

Figure 1 gives the macrostructure of horizontally directional solidified (DS) alloy RN902 in the longitudinal cross section. The chill side is on the right; gravity force is from top to bottom. It shows the grain growth direction, which is basically same with thermal gradient direction, is from right-bottom to top left. The freckles are basically from top to bottom and almost perpendicular to grain growth direction.

Figure 2 shows a freckle structure in IN718 VAR ingot and schematically the solidification conditions. Thermal gradient $\mathrm{G}$ points to up-center of melting pool, while the gravity $g$ points to bottom. The freckle is basically perpendicular to thermal gradient.

The freckle is directly associated with instable interdendritic fluid flow. The main factors to affect the fluid flow are thermal gradient and liquid gravity. The thermal gradient $\mathrm{G}$ determines grain growth direction, and allows the liquid flow along the primary dendrite. The gravity pulls the liquid flow downward if the liquid becomes denser during the solidification. Figure 1 and 2 schematically demonstrate the overall effect of thermal gradient and gravity on the interdendritic flow direction for horizontal DS and VAR. The gravity has a great effect on interdendritic liquid flow and freckle formation. Because of the effect of gravity, the interdendritic liquid flows downward, consequently the freckle appears perpendicular to the grain growth.
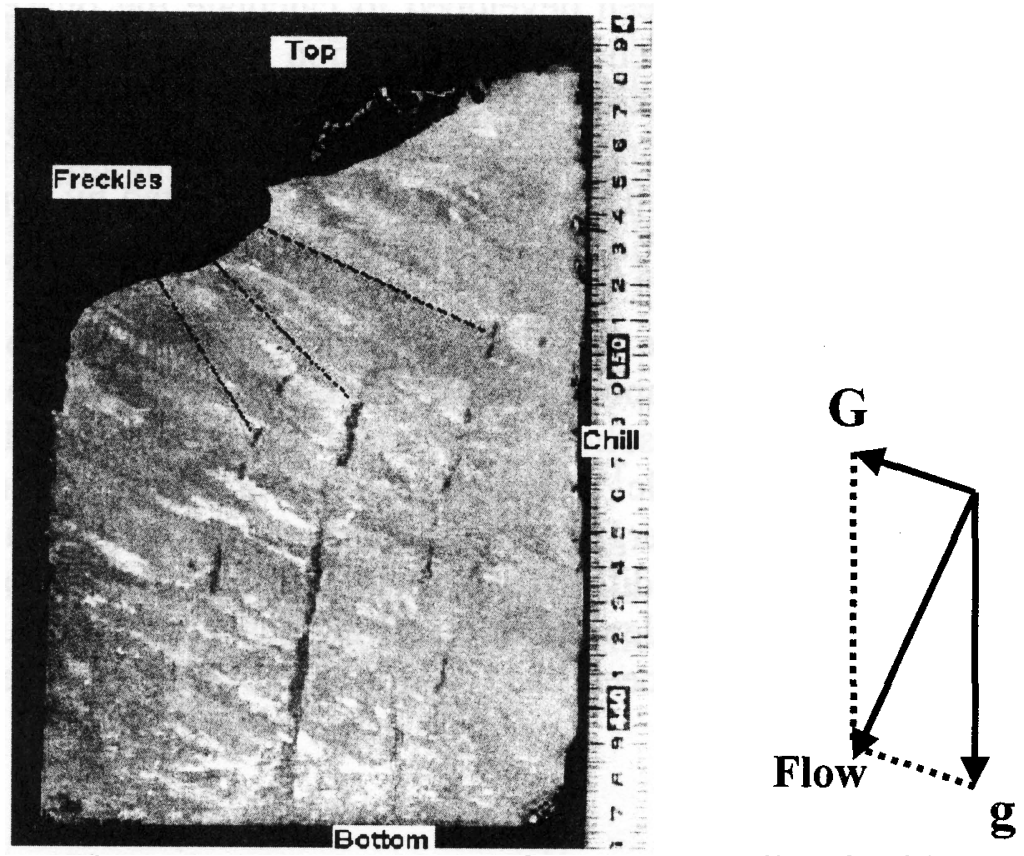

Figure 1. Macrostructure of RN902 revealing freckles.

( $\mathrm{G}$ is the direction of thermal gradient, $g$ is gravity and Flow is interdendritic liquid flow direction) 

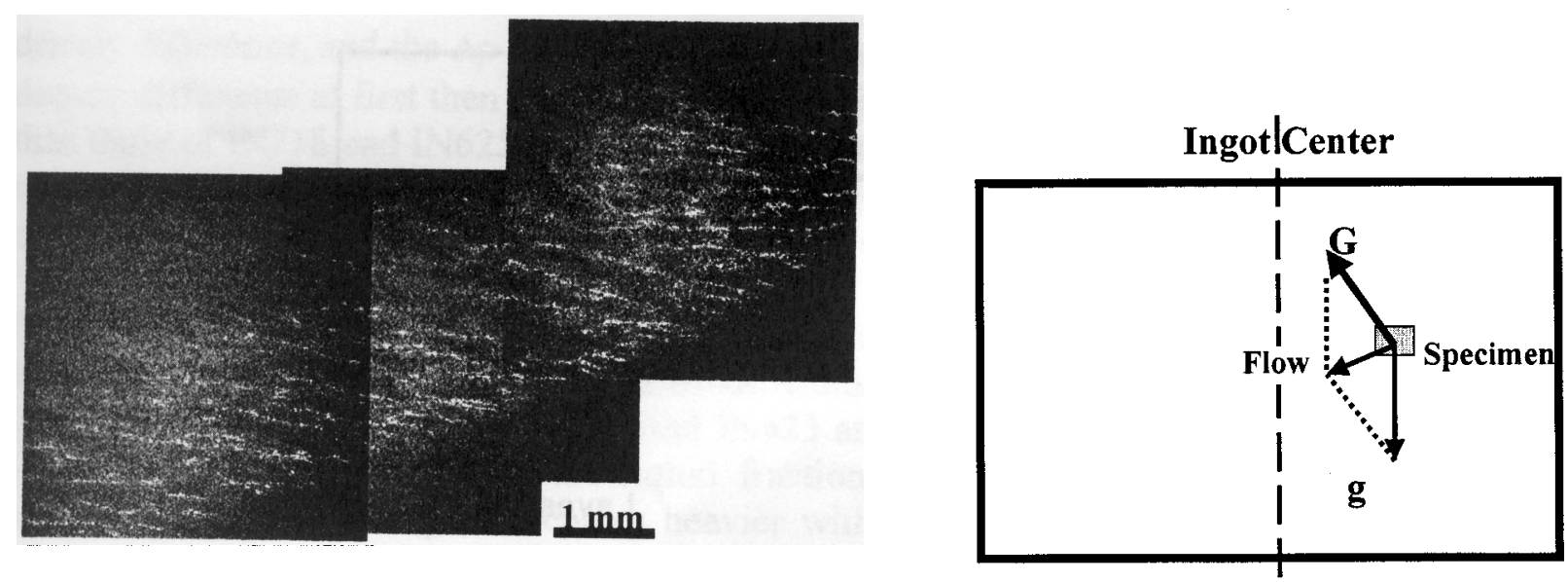

Figure 2. Scanning electron micrography of freckle in IN718 VAR ingot ( $\mathrm{G}$ is the direction of thermal gradient, $\mathrm{g}$ is gravity and Flow is interdendritic liquid flow direction)

\section{Thermodynamic Approach to Calculate the Ra Number}

\section{Liquid Composition and Temperature}

The relationship of liquid composition and temperature about IN718, IN625 and IN706 during the solidification were calculated by ThermoCalc ${ }^{\mathrm{TM}}$ Scheil Simulation Module. Figure 3 shows the calculated results for IN718, as an example of the calculated results. The liquid composition has an obvious change during the solidification. Also shown in Figure 3, the concentrations of some elements have remarkable variation with the decrease of liquid fraction, but some have minor variation. For example, the concentration of $\mathrm{Nb}$ in IN718 alloy increases dramatically as the liquid fraction decreases. Obviously, the heavier the composition changes, the more the microsegregation is.

In Figure 3, the concentration of some elements changes abruptly at certain liquid fraction. This is related to new phase formation during the solidification. For instance, Laves phase was predicted to occur when liquid fraction reaches $18 \%$, which is consistent with literature [14]. Therefore, the abrupt change of liquid composition appears at this liquid fraction. Phase formation also can be observed on the plot of liquid fraction vs. liquid temperature in Figure 3 (b).

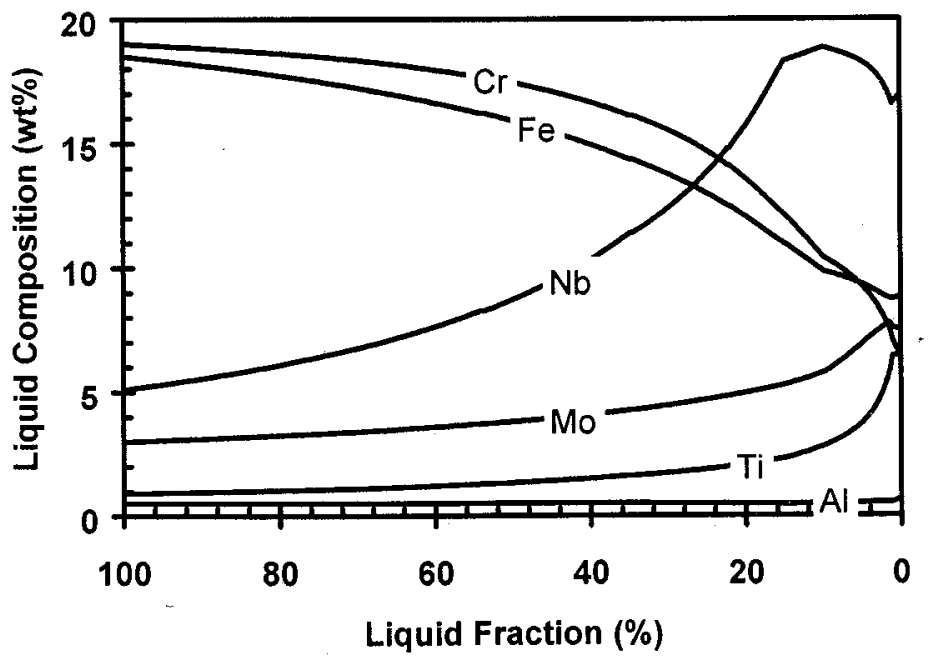

(a) Liquid composition 


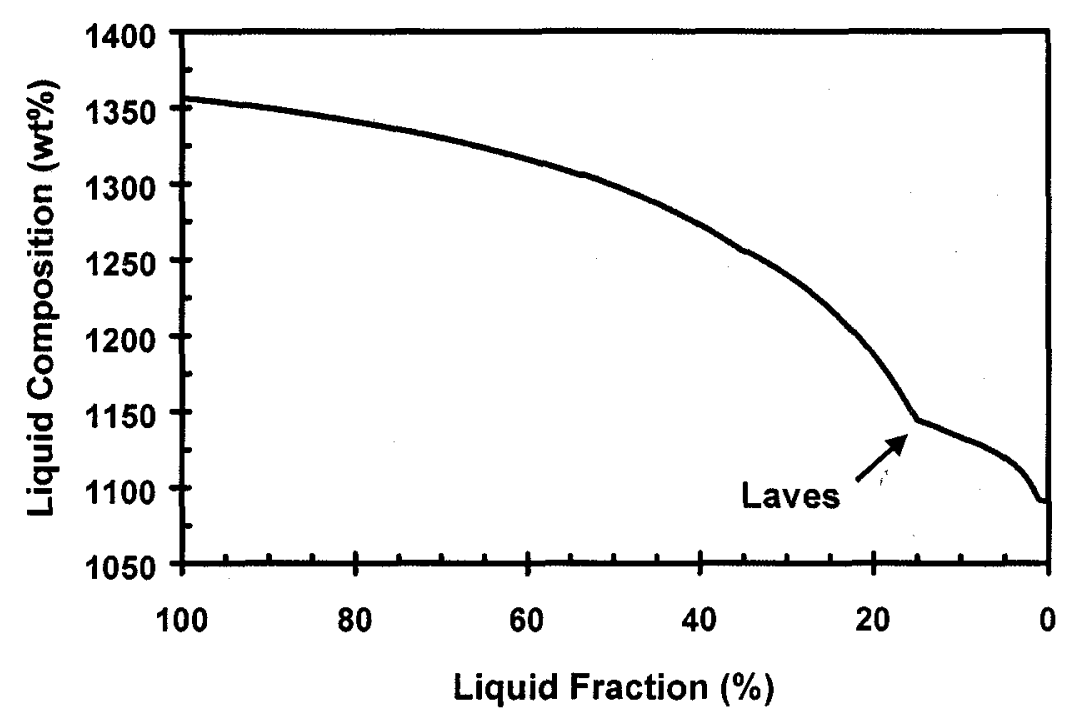

(b) Liquid temperature

Figure 3. Liquid composition and temperature as function of liquid fraction of IN718 during the solidification

\section{Liquid Density Difference}

The molar fraction additive method was used to calculate the liquid density. In order to improve the calculation correctness, the mixing molar volume $\left(\Delta V^{M}\right)$ was introduced by P. K. Sung et al., the modified calculation showed a great reliability [15].

$$
\rho=\frac{\sum_{i} x_{i} A_{i}}{\sum_{i} x_{i} V_{i}+\Delta V^{M}}
$$

where $\rho$ is liquid density, $x_{\mathrm{i}}, A_{\mathrm{i}}$ and $V_{\mathrm{i}}$ are molar fraction, atomic weight and molar volume of an element. The $x_{\mathrm{i}}, V$ and $\Delta V^{M}$ can be calculated by the following equations:

$$
\begin{aligned}
& x_{i}=\frac{C_{i} / A_{i}}{\sum C_{i} / A_{i}} \\
& V=V_{0}\left[1+\left(T-T_{0}\right)^{*} \alpha_{l}\right] \\
& \Delta V^{M}=d_{0}+d_{1} X_{1}+d_{2} X_{2}+d_{3} X_{3}
\end{aligned}
$$

where $T_{0}$ is melting temperature of the element, $V_{0}$ is molar volume at melting temperature, $\alpha_{i}$ is volume expansion coefficient in liquid status. The value of $d_{0}, d_{1}, d_{2}$ and $d_{3}$ are listed in the following Table 2 .

Table 2. Parameters for calculation of mixing molar volume

\begin{tabular}{ccccccc}
\hline $\mathbf{d o}$ & $\mathbf{d}_{\mathbf{1}}$ & $\mathbf{d}_{\mathbf{2}}$ & $\mathbf{d}_{\mathbf{3}}$ & $\mathbf{X}_{\mathbf{1}}$ & $\mathbf{X}_{\mathbf{2}}$ & $\mathbf{X}_{\mathbf{3}}$ \\
\hline-1.4982 & 4.4759 & 5.1988 & 0.43473 & $\mathrm{Al}$ & $\mathrm{Cr}, \mathrm{Ti}$ & $\mathrm{Mo}, \mathrm{W}, \mathrm{Ta}, \mathrm{Nb}, \mathrm{Re}, \mathrm{Hf}$ \\
\hline
\end{tabular}

Figure 4 shows the liquid density difference $(\Delta \rho)$ based on the results of liquid composition and temperature calculated by thermodynamic approach. IN 718 and IN625 have the positive 
density difference, and the $\Delta \rho$ of IN718 is larger than that of IN625. IN706 has a small negative density difference at first then it turns to positive. The overall value $\Delta \rho$ of IN706 is much lower than those of IN718 and IN625 alloys. The results suggest that the interdendritic liquid becomes more and more heavy for alloys IN718 and IN625 during the solidification. IN706 alloy has a much less liquid density difference compared to the other alloys.

Obviously, the liquid density difference is closely related to the initial alloy composition and liquid composition variation during the solidification. Table 1 shows high level of $\mathrm{Nb}$ and low level of Ti and Al elements in IN718 and IN625 and Figure 3 shows the content of Nb in the liquid increase dramatically as the liquid fraction decreases. Therefore, the density of $\mathrm{Nb}$ enriched interdendritic liquid becomes heavier with the increase of solid fraction. For IN706 alloy, the content of $\mathrm{Nb}$ is low and $\mathrm{Ti}$ is high, as a result, the liquid density shows minor change during the solidification.

There are some abrupt changes of density difference for some alloys, especially at the low liquid fraction. Obviously, the abrupt change is related to the phase formation during the solidification. For example, the formation of $\mathrm{Nb}$-enriched Laves phase will dramatically decrease $\mathrm{Nb}$ concentration in liquid phase, and the liquid density decreases rapidly.

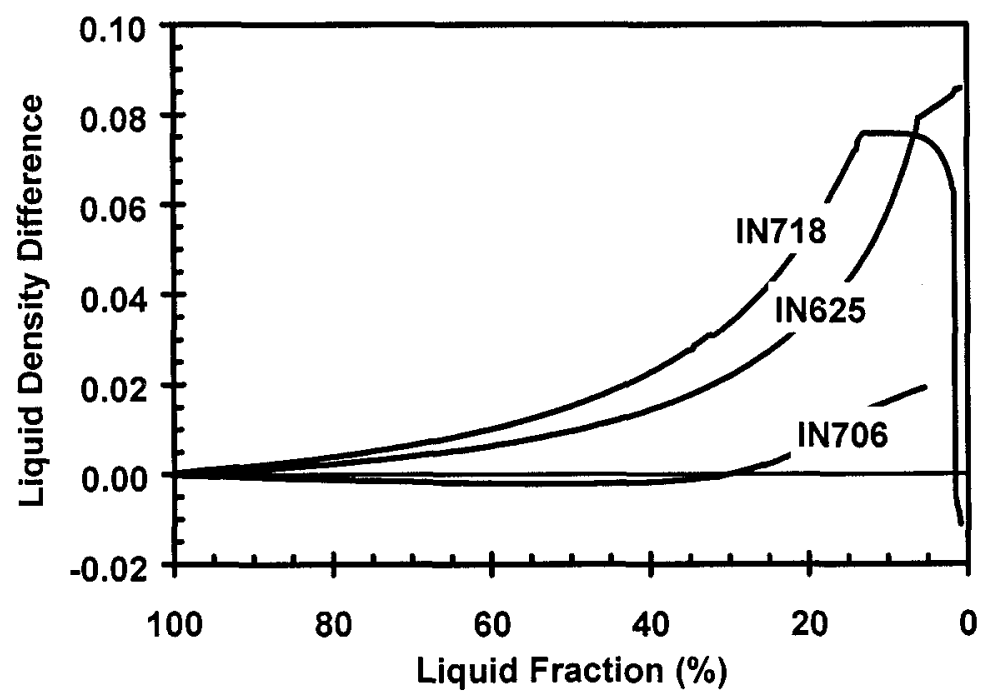

Figure 4 Liquid density difference of IN718, IN625 and IN706 alloys during solidification

\section{Calculated Results of Rayleigh Number}

The method to calculate the permeability used was initially proposed by D.R. Poirier [16], and then improved by W. Yang [10]. Generally, the permeability can be calculated by the equation (7) if the liquid flow along the primary dendrite arm. If the liquid flow perpendicularly to the primary dendrite arm, then equation (8) is applied. Experimental observations indicate that the interdendritic liquid of $\mathrm{Nb}$-bearing superalloys flows perpendicularly to the primary dendrite in the mush zone. Equation (8) was used to calculate the permeability of IN718, IN625 and IN706 alloys.

$$
\Pi=\Delta T / \int_{0}^{\Delta T} f_{L}^{-2} d T
$$




$$
\Pi=\Delta T / \int_{0}^{\Delta T} f_{L}^{-3.34} d T
$$

Figure 5 shows the calculated relative Ra numbers of IN718, IN625 and IN706 alloys. The positive value means the liquid density difference is positive, and negative value means the liquid density difference is negative. The calculated results suggest that the $\mathbb{N} 718$ alloy has the largest relative $\mathrm{Ra}$ number, and IN706 alloy has the lowest relative $\mathrm{Ra}$ number among these three alloys.

The tendency to form freckle of an alloy is related to maximum $\mathrm{Ra}$ number through solidification. The maximum value occurs at 0.4-0.6 liquid fraction. As liquid fraction decrease, the liquid density difference increases, but the permeability decreases. As a result, the maximum relative $\mathrm{Ra}$ number appears about 40-60\% liquid fraction.

There are some abnormal changes of calculated Ra numbers in the lower liquid fraction. These abnormal changes are related to the abrupt changes of liquid density difference, which are usually caused by phase formation during the solidification. However, the overall value of relative $\mathrm{Ra}$ number is not high at low liquid fraction, because liquid flow permeability is dramatically decreased in low liquid fraction. The secondary phase formation, such as Laves, $\delta$ $\mathrm{Ni}_{3} \mathrm{Nb}$ and Carbide phases, has little effect on the freckle formation if the interdendritic secondary phases form at low liquid fraction.

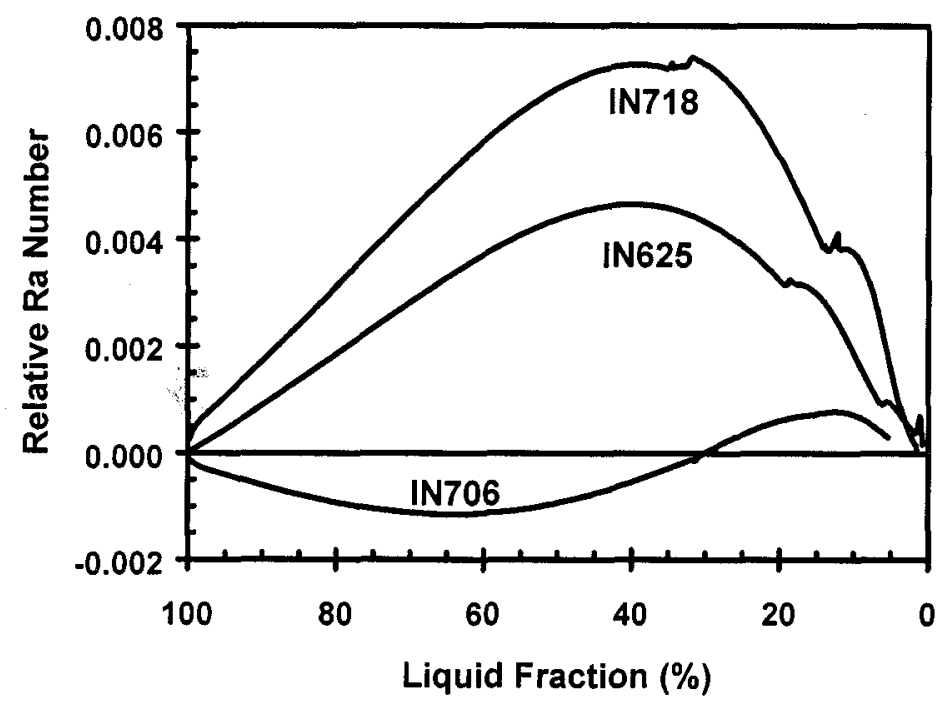

Figure 5 Rayleigh numbers during solidification calculated through thermodynamic approach

\section{Evaluation of the Thermodynamic Approach"}

\section{Ingot Size Capability of Commercial Alloys}

Figure 6 gives state-of-art ingot size capability of superalloys in commercial melting shop [17]. Ingot diameter of $915 \mathrm{~mm}$ can be prepared for alloy 706 , but alloy 718 can only reach to a diameter of $686 \mathrm{~mm}$. It is well known that the ingot size capability is limited by the formation of freckle defect. By Comparing the ingot size capability in Figure 6 to the calculated Ra number in Figure 5, the calculated results of $\mathrm{Ra}$ number through thermodynamic approach is consistent with ingot size capability. 


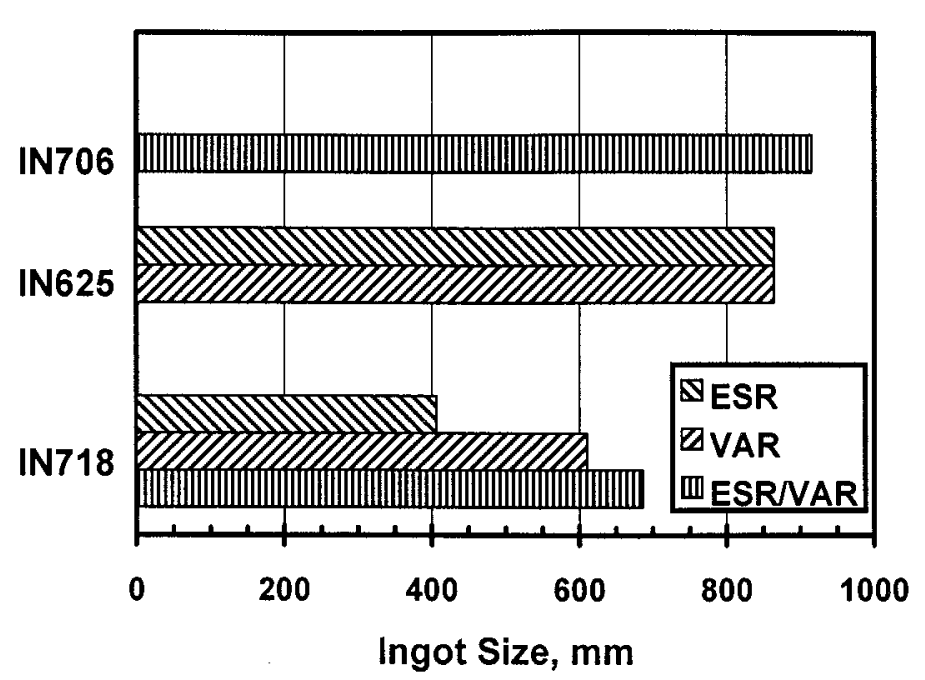

Figure 6. Ingot size capability, Ref. [17]

\section{Comparison of Thermodynamic and Semi-Experimental Approaches}

Figure 7 shows the maximum Ra numbers of alloys 718, 625 and 706 obtained through semiexperimental approach. In comparison, the results from thermodynamic approach (Figure 5) are also plotted. There is minor difference for IN625 and IN706 alloys for the two calculation approaches. In contrast, a significant discrepancy is observed in alloy 718. Although the freckle tendency for the alloys studied here can be explained quantitatively by both approaches, more accurate results are expected through the calculation method. It is suggested to review the Nidatabase for ThermoCalc ${ }^{\mathrm{TM}}$ package, especially during the solidification range (i.e. between liquidus and solidus). If necessary, a new database concentrated on the solidification temperature range will be developed to offer the best benefits of thermodynamic modeling of freckle formation.

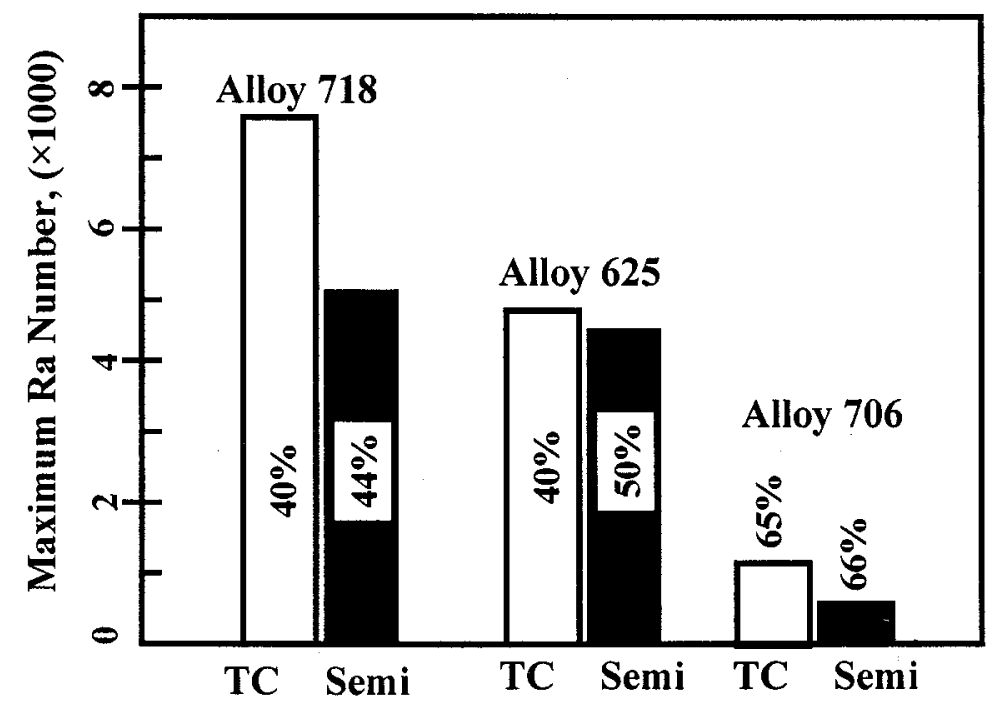

Figure 11. Comparison of maximum Ra numbers by thermodynamic and semi-experimental approaches, (The percentage is the liquid fraction at maximum Ra number) 


\section{Summary}

1. The gravity has an obvious effect on interdendritic liquid flow behavior and freckle formation during the horizontal and VAR/ESR solidification for Nb-bearing superalloys.

2. The solidification simulated by thermodynamic approach, ThermoCalc ${ }^{\mathrm{TM}}$ coupling with its database can provide an effective method to get liquid composition and temperature profile during the solidification.

3. Rayleigh Numbers ( $\mathrm{Ra}$ ) of several Nb-bearing superalloys were calculated based on this thermodynamic approach, to reveal the tendency of freckling.

4. The results of thermodynamic simulation are basically similar to those of semi-experimental analysis. A good agreement was found with the capability of ingot size of the melting shop.

\section{REFERENCES}

1. R. C. Schwant, et al., Superalloys $718,625,706$ and various derivatives, ed. E. A. Loria, TMS, 1997, pp. 141-152.

2. A. D. Helms, C. B. Adasczil and L. A. Jackman, Superalloys 1996, ed. R. D. Kissinger et al, TMS, 1996, pp. 427-433

3. M. C. Flemings, et al., Trans. Metall. AIME, 1967, vol. 239, pp. 1449-1461

4. M. C. Flemings, et al., Trans. Metall. AIME, 1968, vol.242, pp. 41-55

5. C. Beckermann, JOM, 1997, March, pp. 13-17

6. T. M. Pollock et al., Metall. Trans. A, 1996, vol. 27A, pp. 1081-1094

7. P. Auburtin, et al., Metall. Trans. B, 2000,vol. 31B, pp.801-811.

8. S. M. Copley, et al., Metall. Trans., 1970, vol.1 PP. 2193-2204

9. R. J. McDonald, et al., , Metall. Trans., 1970, vol. 1, pp. 1787-1788

10. Wanghong Yang, et al., Metall. Mater. Trans. A, 2001, vol. 32A, pp. 397-406

11. A. F. Crawley, Intl Met. Rev., 1974, vol. 19, pp. 32-48

12. B. Sundman, User aspects of phase diagrams, ed. F. H. Hayes, 1991

13. B. A. Boutwell, Superalloys $718,625,706$ and various derivatives, ed. E. A. Loria, TMS 1997, pp. 99-106

14. S. T. Wlodek, Superalloys 718625,706 and various derivatives, ed. E. A. Loria, TMS, 1994, pp. 167-176

15. P. K. Sung, Mater. Sci. Eng. A, 1997, vol. A231, pp. 189-197

16. D. R. Poirier, Metall. Trans. A, 1988, vol. 10A (9), pp. 2349-2354

17. R. Kennedy, et.al., Advanced Technologies for Superalloy Affordability, ed. Keh-minn Chang, et al., March 2000, TMS, pp. 159-171 